\title{
Low TSH Levels Within Euthyroid Range Could Play a Negative Role on Bone Mineral Density in Postmenopausal Women with Type 2 Diabetes
}

\author{
Congying Liu' \\ Junhong Pan' \\ Song Wen' \\ Thiquynhnga Nguyen' \\ Dongxiang $X u^{\prime}$ \\ Chaoxun Wang' \\ Xinlu Yuan' \\ Zhongqiu Wen ${ }^{2}$ \\ Ligang Zhou ${ }^{1,3}$
}

'Department of Endocrinology, Shanghai Pudong Hospital, Fudan University, Shanghai, 201399, People's Republic of

China; ${ }^{2}$ Department of Information

Center, Shanghai Pudong Hospital, Fudan University, Shanghai, 201399, People's Republic of China; ${ }^{3}$ Shanghai Key Laboratory of Vascular Lesions Regulation and Remodeling, Shanghai Pudong Hospital, Fudan University, Shanghai, 201399, People's Republic of China
Correspondence: Ligang Zhou

Department of Endocrinology, Shanghai Pudong Hospital, Fudan University, 2800

Gongwei Road, Huinan Town, Pudong

New Area, Shanghai, 20I399, People's

Republic of China

Tel +86136II927616

Email zhouligang@yahoo.com
Objective: We aimed to evaluate the relationship between thyroid-stimulating hormone (TSH) and bone mineral density (BMD) in euthyroid type 2 diabetes (T2D).

Methods: This retrospective analysis enrolled 439 T2D patients with normal thyroid function, including 226 males and 213 females. All the female patients were postmenopausal. Serum glycosylated hemoglobin Alc $(\mathrm{HbAlc}), \mathrm{TSH}$, free triiodothyronine $\left(\mathrm{FT}_{3}\right)$, and free thyroxine $\left(\mathrm{FT}_{4}\right)$ concentrations were analyzed. BMD of the lumbar spine $\left(\mathrm{L}_{1}-\mathrm{L}_{4}\right)$, femoral neck, and hip joint was determined using dual-energy X-ray absorptiometry.

Results: The patients were grouped based on tri-sectional quantiles of the TSH levels: 0.55 1.70mIU/L (Group 1), 1.71 2.58mIU/L (Group 2), and 2.59 4.74mIU/L (Group 3). Our data showed that, in male patients, no difference in BMD was identified among groups. In postmenopausal women, unlike at the lumbar spine $(P=0.459)$, the mean BMD at the femoral neck $(P=0.014)$ and hip joint $(P=0.014)$ had a statistical difference among groups and increased with TSH level. In addition, our analysis demonstrated that TSH levels shown no correlation with BMD at all sites in males. However, in females, BMD at the femoral neck $(r=0.156, P=0.023)$ and hip joint $(r=0.172, P=0.012)$ had a positive correlation with TSH levels. After adjusting for age and BMI, multiple regression analysis showed that TSH levels influenced BMD at the femoral neck $(\beta=0.188, P=0.001)$ and hip joint $(\beta=$ $0.204, P=0.001)$ in female patients.

Conclusion: In summary, our data demonstrates that low TSH levels are associated with decreased BMD at the femoral neck and hip joint in postmenopausal T2D women with euthyroidism.

Keywords: type 2 diabetes, thyroid-stimulating hormone, bone mineral density, menopause

\section{Introduction}

Type 2 diabetes (T2D) is characterized by relative insulin deficiency caused by pancreatic $\beta$-cell dysfunction and insulin resistance, and accounts for more than $90 \%$ of all the diabetic subjects. Sustained hyperglycemia enhances the chances of developing of chronic complications in patients with T2D. ${ }^{1}$ Indeed, studies have indicated that osteoporosis is a significant complication of T2D in addition to the other well-established complications. ${ }^{2,3}$ Osteoporosis is a metabolic bone disease characterized by decreased bone mass and destruction of bone microstructure, leading to bone fragility and increased risk of fracture. ${ }^{4}$ Chronic complications of diabetes can induce microvascular damage, resulting in systemic microcirculation disorders, accelerating formation of microthrombosis and abnormal blood supply to 
the bones, thus affecting bone metabolism. ${ }^{5}$ T2D also can cause bone mass destruction and microstructural changes through a variety of other complex factors. ${ }^{6}$

On the other hand, thyroid function is closely related with bone health and an abnormal thyroid function significantly affects bone health. ${ }^{7-9}$ Hyperthyroidism accelerates bone turnover and increases the frequency of bone remodeling. High bone turnover accelerates bone loss and increases susceptibility to osteoporosis and fracture. ${ }^{10}$ Besides, subclinical hyperthyroidism is associated with reduced bone mineral density (BMD) and increased risk of fractures. ${ }^{11-13}$ However, the impact of hypothyroidism and subclinical hypothyroidism on bone health remains unclear. ${ }^{7-9,11}$ Despite slight controversy, recent researches show that thyroid function can affect $\mathrm{BMD}$, even if it is within the normal reference range. Some studies have indicated that, within the normal range, low thyroid-stimulating hormone (TSH) or high thyroid hormone levels contribute to decreased BMD and increased risk of fractures, ${ }^{14-21}$ while others have failed to define such a relationship. ${ }^{22-24}$

Patients with T2D are at a high risk for osteoporosis. However, whether thyroid status influences bone health in patients with $\mathrm{T} 2 \mathrm{D}$ as observed in the general population remains unclear. Here, we interrogated the effect of normal thyroid function on BMD in men and postmenopausal women with T2D patients. This study presents a new approach for the clinical prevention of osteoporosis in patients with T2D using the thyroid function profile.

\section{Materials and Methods}

\section{Participants}

A total of 439 T2D patients, including 226 males and 213 females, hospitalized at the Department of Endocrinology of Shanghai Pudong Hospital from May 1, 2019, to July 31, 2020, were enrolled in this study. All the included women were postmenopausal. TSH, free triiodothyronine $\left(\mathrm{FT}_{3}\right)$, and free thyroxine $\left(\mathrm{FT}_{4}\right)$ values of the participants were within the reference range. Patients with secondary osteoporosis, such as thyroid or parathyroid diseases, drugs induced, or tumors, as well as those with bone metabolic diseases, anti-osteoporosis treatments or drugs use history affecting bone metabolism within the past 6 months were excluded from the study. In addition, patients with acute liver, kidney, heart or brain diseases, mental diseases were excluded.

\section{Measurements}

We recorded height and weight and then computed body mass index (BMI). Fasting veinal blood samples were obtained and analyzed within 2 hours. Glycosylated hemoglobin A1c (HbAlc) was measured and we tested serum $\mathrm{TSH}, \mathrm{FT}_{3}$, and $\mathrm{FT}_{4}$ using immunoluminometric assay. The reference range for the TSH was $0.55 \mathrm{mIU} / \mathrm{L} \sim 4.78 \mathrm{mIU} / \mathrm{L}$. BMD at the lumbar spine $\left(\mathrm{L}_{1}-\mathrm{L}_{4}\right)$, femur neck, as well as hip joint was evaluated by dual-energy X-ray absorptiometry (DXA).

\section{Statistical Analysis}

Statistical analyses were performed using SPSS 22.0 version and GraphPad Prism v.8. Kolmogorov-Smirnov test was used to evaluate the normal distribution of the data. The normal distribution data was described by $\bar{X} \pm S$. In addition, the Student's $t$-test was used to compare the two groups while one-way ANOVA was used to assess variances among the three groups. We then performed post hoc comparison using $L S D-t$, while Pearson correlation analysis was used to analyze the correlation among variables. On the other hand, non-normal distribution data was represented by $M(Q 25, Q 75)$. Mann-Whitney $U$-test was used to compare between two groups, while KruskalWallis $H$-test was used for comparison among three groups. Spearman correlation analysis was used to evaluate the correlation among variables. In addition, multivariate regression analysis was performed to explore the relationship between the TSH and BMD after adjusting for age and BMI. A $P$ value $<0.05$ was considered statistically significant.

\section{Results}

\section{Clinical Baseline Characteristics}

The baseline characteristics for the T2D patients with normal thyroid function were shown in Table 1. Compared with males, female patients were older, had a longer diabetic duration, and their BMD was dramatically reduced at the lumbar spine, femoral neck, and hip joint.

\section{BMD in Different TSH Concentration Groups}

The patients were grouped based on tri-sectional quantiles of the TSH levels: $0.55 \sim 1.70 \mathrm{mIU} / \mathrm{L}$ (Group 1), 1.71 2.58mIU/ L (Group 2), and 2.59 4.74mIU/L (Group 3). Our data showed that, in male patients, there was no difference in age, BMI, duration of diabetes, HbAlc as well as BMD 
Table I Baseline Characteristics of the Study Participants

\begin{tabular}{|c|c|c|c|}
\hline Variables & Male & Female & $P$ \\
\hline $\mathbf{N}$ & 226 & 213 & \\
\hline Age (year) & $64.10 \pm 10.50$ & $67.38 \pm 10.37$ & $0.001 * *$ \\
\hline BMI $\left(\mathrm{kg} / \mathrm{m}^{2}\right)$ & $25.33 \pm 3.33$ & $25.48 \pm 3.78$ & 0.674 \\
\hline HbAlc (\%) & $9.37 \pm 2.07$ & $9.38 \pm 2.30$ & 0.988 \\
\hline Diabetic Duration (year) & $10(3,15)$ & $10(6,18)$ & $0.017^{*}$ \\
\hline $\mathrm{FT}_{3}(\mathrm{pmol} / \mathrm{L})$ & $4.66 \pm 0.54$ & $4.33 \pm 0.48$ & $<0.00 I^{* *}$ \\
\hline $\mathrm{FT}_{4}(\mathrm{pmol} / \mathrm{L})$ & $15.76 \pm 2.11$ & $\mid 5.38 \pm 2.01$ & 0.053 \\
\hline TSH (mlU/L) & $2.06 \pm 0.96$ & $2.41 \pm 0.98$ & $<0.001 * *$ \\
\hline$B M D L_{1}\left(g / \mathrm{cm}^{2}\right)$ & $0.97 \pm 0.17$ & $0.8 \mathrm{I} \pm 0.15$ & $<0.001 * *$ \\
\hline $\mathrm{BMD} \mathrm{L}_{2}\left(\mathrm{~g} / \mathrm{cm}^{2}\right)$ & $1.01 \pm 0.18$ & $0.84 \pm 0.15$ & $<0.001 * *$ \\
\hline $\mathrm{BMD} \mathrm{L}_{3}\left(\mathrm{~g} / \mathrm{cm}^{2}\right)$ & $1.05 \pm 0.20$ & $0.88 \pm 0.16$ & $<0.001 * *$ \\
\hline $\mathrm{BMD} \mathrm{L}_{4}\left(\mathrm{~g} / \mathrm{cm}^{2}\right)$ & $1.04 \pm 0.20$ & $0.88 \pm 0.17$ & $<0.001 * *$ \\
\hline BMD Lumbar spine $\left(\mathrm{g} / \mathrm{cm}^{2}\right)$ & $1.03 \pm 0.19$ & $0.86 \pm 0.16$ & $<0.001 * *$ \\
\hline BMD Femur neck $\left(\mathrm{g} / \mathrm{cm}^{2}\right)$ & $0.78 \pm 0.13$ & $0.66 \pm 0.12$ & $<0.001 * *$ \\
\hline BMD Hip joint $\left(\mathrm{g} / \mathrm{cm}^{2}\right)$ & $0.92 \pm 0.14$ & $0.80 \pm 0.17$ & $<0.001 * *$ \\
\hline
\end{tabular}

Notes: $* P<0.05 ; * * P<0.01$.

Abbreviations: BMI, body mass index; $\mathrm{HbAlc}$, glycosylated hemoglobin $\mathrm{Alc}$; $\mathrm{FT}_{3}$, free triiodothyronine; $\mathrm{FT}_{4}$, free thyroxine; $\mathrm{TSH}$, thyroid-stimulating hormone; $\mathrm{BMD}$, bone mineral density.

(Table 2). On the other hand, whereas there were no statistically differences in age, BMI, duration of diabetes, and HbAlc, the female patients showed differences in BMD (femoral neck: $P=0.014$, hip joint: $P=0.014$ ), and increased with TSH level (Table 3$)$. In addition, there was a significant decline in the BMD at the femoral neck $(P=0.004)$ and hip joint $(P=0.004)$ in females in Group 1 compared to Group 3 (Figure 1).

\section{Correlation Between BMD and TSH Concentration}

For the correlation analysis, BMD was used as a dependent variable, while age, BMI, diabetic duration, $\mathrm{HbAlc}$, and TSH were used as independent variables. The results showed that, in males, BMD at the lumbar spine was positively correlated with

Table 2 BMD in Different TSH Concentration Groups (Male)

\begin{tabular}{|l|l|l|l|l|}
\hline Variables & Group I & Group 2 & Group 3 & $P$ \\
\hline $\mathbf{N}$ & 96 & 69 & 61 & \\
\hline Age (year) & $62.73 \pm 9.89$ & $64.45 \pm 11.35$ & $65.87 \pm 10.32$ & 0.179 \\
BMI (kg/m $\left.{ }^{2}\right)$ & $25.22 \pm 3.19$ & $25.19 \pm 3.35$ & $25.68 \pm 3.55$ & 0.631 \\
HbAlc (\%) & $9.72 \pm 2.08$ & $9.23 \pm 2.11$ & $8.99 \pm 1.93$ & 0.079 \\
Diabetic Duration (year) & $7.5(2,14.75)$ & $10(3.5,16)$ & $10(4.5,18.5)$ & 0.153 \\
BMD Lumbar spine $\left(\mathrm{g} / \mathrm{cm}^{2}\right)$ & $1.01 \pm 0.19$ & $1.03 \pm 0.17$ & $1.06 \pm 0.20$ & 0.277 \\
BMD Femur neck $\left(\mathrm{g} / \mathrm{cm}^{2}\right)$ & $0.78 \pm 0.15$ & $0.77 \pm 0.12$ & $0.78 \pm 0.12$ & 0.939 \\
BMD Hip joint $\left(\mathrm{g} / \mathrm{cm}^{2}\right)$ & $0.92 \pm 0.14$ & $0.93 \pm 0.14$ & $0.93 \pm 0.13$ & 0.909 \\
\hline
\end{tabular}

Abbreviations: Group I, TSH 0.55 1.70mIU/L; Group 2, TSH I.7I 2.58mIU/L; Group 3, TSH 2.59 4.74mIU/L; BMI, body mass index; HbAlc, glycosylated hemoglobin Alc; BMD, bone mineral density; TSH, thyroid-stimulating hormone.
Table 3 BMD in Different TSH Concentration Groups (Female)

\begin{tabular}{|l|l|l|l|l|}
\hline Variables & Group I & Group 2 & Group 3 & P \\
\cline { 1 - 4 } N & $\mathbf{5 2}$ & $\mathbf{7 7}$ & $\mathbf{8 4}$ & \\
\hline Age (year) & $68.87 \pm 10.25$ & $65.61 \pm 9.56$ & $68.10 \pm 10.04$ & 0.157 \\
BMI $\left(\mathrm{kg} / \mathrm{m}^{2}\right)$ & $26.01 \pm 4.29$ & $25.35 \pm 3.75$ & $25.26 \pm 3.47$ & 0.502 \\
HbAlc $(\%)$ & $9.32 \pm 2.44$ & $9.65 \pm 2.19$ & $9.16 \pm 2.31$ & 0.397 \\
Diabetic Duration (year) & $10(8,19.75)$ & $10(5,18)$ & $10(4.25,16.50)$ & 0.471 \\
BMD Lumbar spine $\left(\mathrm{g} / \mathrm{cm}^{2}\right)$ & $0.85 \pm 0.14$ & $0.86 \pm 0.16$ & $0.88 \pm 0.16$ & 0.459 \\
BMD Femur neck $\left(\mathrm{g} / \mathrm{cm}^{2}\right)$ & $0.63 \pm 0.12$ & $0.66 \pm 0.12$ & $0.69 \pm 0.12$ & $0.014 *$ \\
BMD Hip joint $\left(\mathrm{g} / \mathrm{cm}^{2}\right)$ & $0.76 \pm 0.13$ & $0.79 \pm 0.16$ & $0.85 \pm 0.19$ & $0.014 *$ \\
\hline
\end{tabular}

Note: $* P<0.05$.

Abbreviations: Group I, TSH 0.55 1.70mIU/L; Group 2, TSH I.7I 2.58mlU/L; Group 3, TSH 2.59 4.74mIU/L; BMI, body mass index; HbAlc, glycosylated hemoglobin Alc; BMD, bone mineral density; TSH, thyroid-stimulating hormone.

age and BMI. Besides, BMD at the femoral neck and hip joint was negatively associated with age but positively related to BMI. BMD at all sites had no relationship with TSH (Table 4). In postmenopausal women, BMD at the lumbar spine had a positive relationship with BMI but negatively correlated with age. In addition, BMD at the femoral neck and hip joint exhibited a positive association with BMI and $\mathrm{TSH}$, but a negative relationship with age and diabetic duration (Table 5).

\section{Factors Influencing BMD at the Femoral Neck and Hip Joint in Postmenopausal T2D Women}

For stepwise regression analysis, BMD at the femoral neck and hip joint were considered to be dependent variables, while age, BMI, diabetic duration, HbAlc, and TSH were independent variables. At the femoral neck, age, BMI and TSH influenced BMD (the adjusted $R^{2}=0.288, F=29.599$, $P<0.001)$, with age making the strongest contribution $(\beta=-$ $0.468, P<0.001)$, followed by BMI $(\beta=0.192, P=0.001)$, and TSH $(\beta=0.188, P=0.001)$ (Table 6). On the other hand, at the hip joint, the data showed that age, BMI, and TSH were the influencing factors of hip joint (the adjusted $\left.R^{2}=0.257, F=25.381, P<0.001\right)$, and age had the greatest influence $(\beta=-0.345, P<0.001)$, followed by BMI $(\beta=$ $0.310, P<0.001)$, and TSH $(\beta=0.204, P=0.001)$ (Table 7).

\section{Discussion}

This study included T2D patients with normal thyroid function. Our correlation analysis demonstrated that age and BMI were strongly correlated with BMD at all sites. We showed that only the BMD at the lumbar spine was positively related with age in males, while the others were negatively correlated. 
A

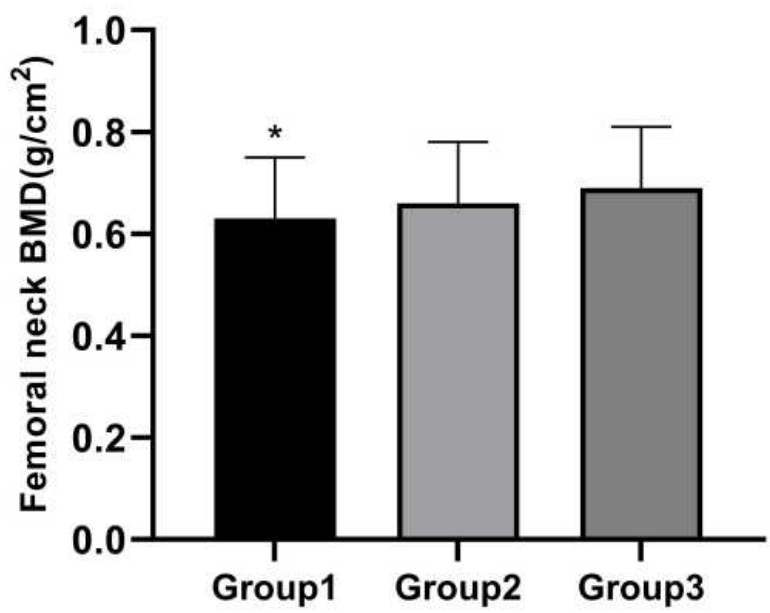

B

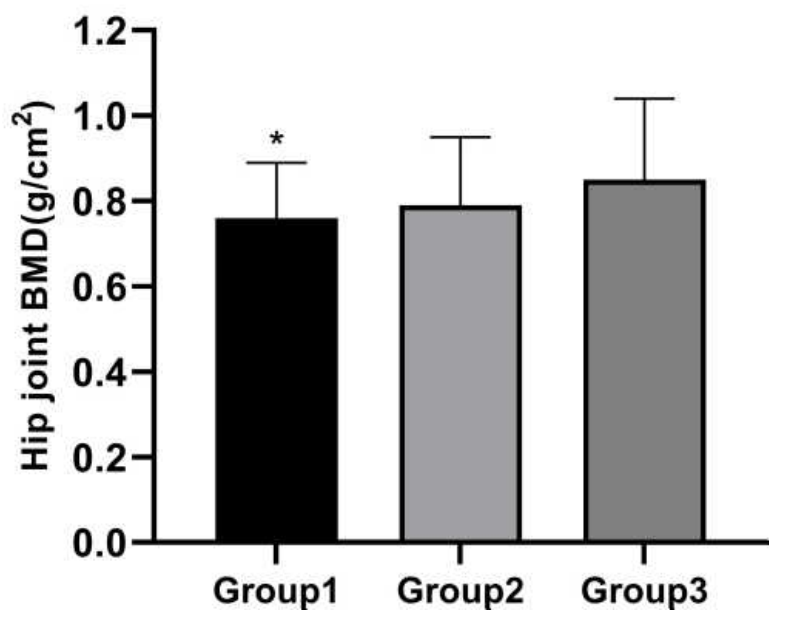

Figure I Comparison of femoral neck BMD (A) and hip joint BMD (B) among the different TSH concentration groups in T2D female patients. The BMD at the femoral neck and hip joint increased with TSH level. $* P<0.05$ compared with Group 3.

Abbreviations: T2D, type 2 diabetes; BMD, bone mineral density; Group I, TSH 0.55 1.70mIU/L; Group 2, TSH I.7I 2.58mIU/L; Group 3, TSH 2.59 4.74mIU/L.

In agreement with previous studies, our data showed that BMD at all sites had a positive correlation with BMI. ${ }^{25,26}$ We could, however, not demonstrate and correlation between TSH and BMD at all sites in male patients. ${ }^{27}$ On the other hand, in postmenopausal women, high levels of TSH within the normal range were associated with high BMD at the femoral neck and hip joint, but not with BMD at the lumbar spine. Multiple regression analysis showed that the positive correlation between TSH levels and BMD for the two sites did not change after adjustment for age and BMI. This is consistent with the results in many previous studies involving healthy subjects without T2D. ${ }^{16,20,21}$

Table 4 Correlation Between BMD at Different Sites and TSH Concentration (Male)

\begin{tabular}{|l|l|l|l|l|l|l|}
\hline \multirow{2}{*}{ Variables } & \multicolumn{2}{l|}{ Lumbar Spine } & \multicolumn{2}{l|}{ Femoral Neck } & \multicolumn{2}{l|}{ Hip Joint } \\
\cline { 2 - 7 } & $\boldsymbol{r} / \boldsymbol{r}_{\boldsymbol{s}}$ & $\boldsymbol{P}$ & $\boldsymbol{r} / \boldsymbol{r}_{\boldsymbol{s}}$ & $\boldsymbol{P}$ & $\boldsymbol{r} / \boldsymbol{r}_{\boldsymbol{s}}$ & $\boldsymbol{P}$ \\
\hline Age (year) & 0.140 & $0.035^{*}$ & -0.181 & $0.006^{*}$ & -0.135 & $0.042^{*}$ \\
BMI (kg/m) & 0.286 & $<0.00 I^{* *}$ & 0.332 & $<0.00 I^{* *}$ & 0.329 & $<0.00 I^{* *}$ \\
HbAlc (\%) & -0.002 & 0.971 & 0.126 & 0.059 & 0.059 & 0.376 \\
Diabetic Duration (year) & 0.106 & 0.114 & -0.001 & 0.988 & 0.029 & 0.665 \\
TSH (mlU/L) & 0.101 & 0.130 & 0.020 & 0.761 & 0.039 & 0.562 \\
\hline
\end{tabular}

Notes: $* P<0.05 ; * * P<0.01$.

Abbreviations: BMD, bone mineral density; HbAlc, glycosylated hemoglobin Alc; TSH, thyroid-stimulating hormone; BMI, body mass index.

Table 5 Correlation Between BMD at Different Sites and TSH Concentration (Female)

\begin{tabular}{|c|c|c|c|c|c|c|}
\hline \multirow[t]{2}{*}{ Variables } & \multicolumn{2}{|c|}{ Lumbar Spine } & \multicolumn{2}{|c|}{ Femoral Neck } & \multicolumn{2}{|c|}{ Hip Joint } \\
\hline & $r / r_{s}$ & $P$ & $r / r_{s}$ & $P$ & $r / r_{s}$ & $\boldsymbol{P}$ \\
\hline Age (year) & -0.260 & $<0.001 * *$ & -0.479 & $<0.00 I^{* *}$ & -0.368 & $<0.001 * *$ \\
\hline BMI $\left(\mathrm{kg} / \mathrm{m}^{2}\right)$ & 0.268 & $<0.001 * *$ & 0.234 & $0.00 I^{* *}$ & 0.338 & $<0.001 * *$ \\
\hline $\mathrm{HbAlc}(\%)$ & -0.015 & 0.825 & 0.079 & 0.250 & 0.076 & 0.269 \\
\hline Diabetic Duration (year) & -0.001 & 0.987 & -0.204 & $0.003^{* *}$ & -0.168 & $0.014 *$ \\
\hline TSH (mIU/L) & 0.080 & 0.243 & 0.156 & $0.023^{*}$ & 0.172 & $0.012 *$ \\
\hline
\end{tabular}

Notes: $* P<0.05 ; * * P<0.01$.

Abbreviations: BMD, bone mineral density; HbAlc, glycosylated hemoglobin Alc; TSH, thyroid-stimulating hormone; BMI, body mass index. 
Table 6 Multiple Regression Analysis of the Factors Influencing BMD at the Femoral Neck in Postmenopausal Female T2D Patients

\begin{tabular}{|l|l|l|l|l|l|}
\hline \multirow{2}{*}{ Variables } & \multicolumn{5}{|l|}{ Femoral Neck $\boldsymbol{R}^{\mathbf{2}}=\mathbf{0 . 2 8 8} \boldsymbol{P}<\mathbf{0 . 0 0 I}$} \\
\cline { 2 - 6 } & B & SE & $\boldsymbol{\beta}$ & $\boldsymbol{t}$ & $\boldsymbol{P}$ \\
\hline Age (year) & -0.006 & 0.001 & -0.468 & 8.014 & $<0.00 I^{* *}$ \\
BMI $\left(\mathrm{kg} / \mathrm{m}^{2}\right)$ & 0.006 & 0.002 & 0.192 & 3.286 & $0.00 I^{* *}$ \\
TSH (mlU/L) & 0.023 & 0.007 & 0.188 & 3.244 & $0.00 I^{* *}$ \\
\hline
\end{tabular}

Note: $* * P<0.01$.

Abbreviations: $\mathrm{BMD}$, bone mineral density; T2D, type 2 diabetes; $\mathrm{BMI}$, body mass index; $\mathrm{TSH}$, thyroid-stimulating hormone; $\mathrm{B}$, unstandardized coefficient; $\beta$, standardized coefficient.

Table 7 Multiple Regression Analysis of the Factors Influencing BMD at the Hip Joint in Postmenopausal Female T2D Patients

\begin{tabular}{|l|l|l|l|l|l|}
\hline \multirow{2}{*}{ Variables } & \multicolumn{5}{|l|}{ Hip joint $\boldsymbol{R}^{2}=\mathbf{0 . 2 5 7} \mathbf{P}<\mathbf{0 . 0 0 I}$} \\
\cline { 2 - 6 } & B & SE & $\boldsymbol{\beta}$ & $\boldsymbol{t}$ & $\boldsymbol{P}$ \\
\hline Age (year) & -0.006 & 0.001 & -0.345 & 5.782 & $<0.00 I^{* *}$ \\
BMI (kg/m $\left.{ }^{2}\right)$ & 0.014 & 0.003 & 0.310 & 5.205 & $<0.00 I^{* *}$ \\
TSH (mlU/L) & 0.035 & 0.010 & 0.204 & 3.439 & $0.00 I^{* *}$ \\
\hline
\end{tabular}

Note: $* * P<0.01$.

Abbreviations: BMD, bone mineral density; T2D, type 2 diabetes; $\mathrm{BMI}$, body mass index; TSH, thyroid-stimulating hormone; $B$, unstandardized coefficient; $\beta$, standardized coefficient.

Serum thyroid hormone and TSH are the basic indicators of thyroid function. Since TSH is more sensitive to changes in the thyroid status, it is considered the mainstay indicator to distinguish between normal and abnormal thyroid function. Besides, it has been demonstrated that hyperthyroidism and subclinical hyperthyroidism are associated with decreased BMD and increased fracture risk. In this study, low levels TSH within the normal range were associated with decreased BMD in the femoral neck and hip joint in postmenopausal women with T2D. We hypothesized that mild subclinical hyperthyroidism might also be present in patients with TSH at the low levels of the normal range. The TSH reference range only includes $95 \%$ of the reference population, and the lower limit of the reference is relatively normal. Moreover, endocrine and metabolic disorders in T2D patients might also influence the reference range of $\mathrm{TSH}^{28,29}$ Therefore, TSH levels at the low normal range may also affect the BMD.

It has been thought that bone abnormalities caused by hyperthyroidism are due to thyroid hormones rather than TSH. Recent exploration has shown that TSH may play a direct role in bone protection. In 1998, Inoue et al first reported that TSH receptor could be expressed in osteoblast- like rat osteosarcoma cells. ${ }^{30}$ Subsequently, studies in TSH receptor knockout mice demonstrated that osteoblasts and osteoclasts expressed TSH receptor, and TSH receptordeficient mice was more prone to develop high bone turnover osteoporosis. ${ }^{31}$ Hase et al showed that TSH could inhibit the production of TNF- $\alpha$ and thus adversely regulate osteoclast differentiation. ${ }^{32}$ In addition, Sun et al showed that an injection of recombinant TSH had a strong anti-bone resorption effect on bones in rats. ${ }^{33}$ Besides, bone phenotypes were compared between wild-type and TSH receptor knockout mice and showed that both thyroid hormone and TSH can affect the bone. $^{34}$

In addition, gender has been closely associated with BMD. In this study, compared with men, BMD decreased significantly at all sites in postmenopausal female patients, suggesting that gender influences bone metabolism. Data has shown that postmenopausal females have higher bone turnover. It has been established that postmenopausal osteoporosis occurs mainly of the decreased estrogen level, which reduces the inhibitory effect of estrogen on osteoclasts, and increases the number of osteoclasts, reduces apoptosis, and prolongs life span, as well as enhances bone resorption function. Although there was an increase in osteoblasts that contributed to bone formation, it was not sufficient to compensate for excessive bone resorption. The active and unbalanced bone remodeling results in thinness or fracture of trabecular bones, increased cortical bone porosity, and reduced bone strength. ${ }^{35}$ Our study showed that low normal TSH levels could lead to decreased BMD at the femoral neck and hip joint in women, but not in men. Siru et al showed that TSH within the euthyroid range had no correlation with fracture risk in men compared to women. ${ }^{27}$ In addition, the risk of fracture of thyroxine replacement therapy was also dependent on sex. ${ }^{36}$ These studies may indicate that postmenopausal women are more susceptible to thyroid status than men.

In postmenopausal female patients, low normal levels of TSH may lead to decreased BMD at the femoral neck and hip joint but not at the lumbar spine. Similarly, Van der Deure and Murphy et al showed that low normal TSH levels or high thyroid hormone levels were only associated with BMD at the femoral neck, but not at the lumbar spine. ${ }^{16,19}$ This might define the selectivity of the thyroid action to the lumbar spine and the femur. Thyroid hormones affect the cortex more than trabeculae, examining areas rich in cortical bone, such as the forearm and femoral neck, may have a greater impact than measuring only areas containing trabeculae. ${ }^{37}$ In a series of 
animal experiments, Suwanwalaikorn et al reported that TSH inhibitor L-thyroxine reduced BMD in the femur of rats, but not in the spine. ${ }^{38-40}$ And gene expression markers in osteoblasts and osteoclasts were significantly increased in femur, but not in the lumbar spine. Longterm overdose of L-thyroxine in adult rats selectively affected the femoral bone over the vertebrae. ${ }^{39}$ Therefore, we hypothesized that TSH may exert differential effects on the lumbar spine, femoral neck, and hip joint due to the specificity of the bone site. In addition, this could also be due to extrapyramidal calcification, especially osteophytes. ${ }^{41-43}$ Orwoll et al demonstrated that subjects with osteophytes had higher spinal BMD, but not at the femoral site. ${ }^{42}$ And osteophytes have a greater influence in men. ${ }^{44}$ The results may also explain the positive correlation between lumbar spine BMD and age in males. Extra vertebral calcification interferes with the measurement of lumbar BMD. Besides, this measurement error might also interfere with the observation of the effect of TSH on lumbar spine BMD.

This study was conducted retrospectively and collected data from a single center. We did not fully consider other factors such as diet, lifestyle and labor intensity. The influence of sex hormones and menopausal years in postmenopausal women was not analyzed. However, our study supplemented the effect of normal thyroid function on bone health in patients with T2D, and separately investigated the effects in men and postmenopausal women. There is need for further exploration involving large prospective cohort studies.

In summary, our data demonstrates that low TSH levels are associated with decreased BMD at the femoral neck and hip joint in postmenopausal T2D women with euthyroidism. However, we could not find any association between serum TSH and BMD in T2D men within euthyroid range.

\section{Ethical Statement}

This study was approved by Shanghai Pudong Hospital affiliated with Fudan University (Shanghai, China), and followed the guidelines outlined in the Declaration of Helsinki. Informed written consent was obtained from the patients for the review of the medical data and publication of this study.

\section{Funding}

This work was supported by the Project of Key Medical Discipline of Pudong Hospital of Fudan University (Zdxk2020-11), the Project of Key Medical Specialty and
Treatment Center of Pudong Hospital of Fudan University (Zdzk2020-24), and National Natural Science Foundation of China (81370932), Outstanding Leaders Training Program of Pudong Health Bureau of Shanghai (PWR12014-06), the Outstanding Clinical Discipline Project of Shanghai Pudong (PWYgy-2018-08), the Natural Science Foundation of China (21675034), Shanghai Natural Science Foundation (19ZR1447500).

\section{Disclosure}

The authors claim that there is no conflict of interest.

\section{References}

1. Vijan S. Type 2 diabetes. Ann Intern Med. 2019;171(9):Itc65-itc80. doi:10.7326/AITC201911050

2. Janghorbani M, Van Dam RM, Willett WC, et al. Systematic review of type 1 and type 2 diabetes mellitus and risk of fracture. $A m$ J Epidemiol. 2007;166(5):495-505. doi:10.1093/aje/kwm106

3. Vestergaard P. Discrepancies in bone mineral density and fracture risk in patients with type 1 and type 2 diabetes-a meta-analysis. Osteoporos Int. 2007;18(4):427-444. doi:10.1007/s00198-006-02534

4. Ensrud KE, Crandall CJ. Osteoporosis. Ann Intern Med. 2017;167(3): Itc17-itc32. doi:10.7326/AITC201708010

5. Shanbhogue VV, Hansen S, Frost M, et al. Bone disease in diabetes: another manifestation of microvascular disease? Lancet Diabetes Endocrinol. 2017;5(10):827-838. doi:10.1016/S2213-8587(17) 30134-1

6. Napoli N, Chandran M, Pierroz DD, et al. Mechanisms of diabetes mellitus-induced bone fragility. Nat Rev Endocrinol. 2017;13 (4):208-219. doi:10.1038/nrendo.2016.153

7. Delitala AP, Scuteri A, Doria C. Thyroid hormone diseases and osteoporosis. J Clin Med. 2020;9(4):1034. doi:10.3390/jcm9041034

8. Williams GR, Bassett JHD. Thyroid diseases and bone health. J Endocrinol Invest. 2018;41(1):99-109. doi:10.1007/s40618-0170753-4

9. Bassett JH, Williams GR. Role of thyroid hormones in skeletal development and bone maintenance. Endocr Rev. 2016;37 (2):135-187.

10. Nicholls JJ, Brassill MJ, Williams GR, et al. The skeletal consequences of thyrotoxicosis. J Endocrinol. 2012;213(3):209-221. doi:10.1530/JOE-12-0059

11. Blum MR, Bauer DC, Collet T-H, et al. Subclinical thyroid dysfunction and fracture risk: a meta-analysis. JAMA. 2015;313 (20):2055-2065. doi:10.1001/jama.2015.5161

12. Murphy E, Williams GR. The thyroid and the skeleton. Clin Endocrinol (Oxf). 2004;61(3):285-298. doi:10.1111/j.13652265.2004.02053.x

13. Wirth CD, Blum MR, da Costa BR, et al. Subclinical thyroid dysfunction and the risk for fractures: a systematic review and meta-analysis. Ann Intern Med. 2014;161(3):189-199. doi:10.7326/ M14-0125

14. van Rijn LE, Pop VJ, Williams GR. Low bone mineral density is related to high physiological levels of free thyroxine in peri-menopausal women. Eur $J$ Endocrinol. 2014;170(3):461-468. doi:10.1530/EJE-13-0769

15. Roef G, Lapauw B, Goemaere S, et al. Thyroid hormone status within the physiological range affects bone mass and density in healthy men at the age of peak bone mass. Eur $J$ Endocrinol. 2011;164(6):1027-1034. doi:10.1530/EJE-10-1113 
16. van der Deure WM, Uitterlinden AG, Hofman A, et al. Effects of serum TSH and FT4 levels and the TSHR-Asp727Glu polymorphism on bone: the Rotterdam Study. Clin Endocrinol (Oxf). 2008;68 (2):175-181. doi:10.1111/j.1365-2265.2007.03016.x

17. Morris MS. The association between serum thyroid-stimulating hormone in its reference range and bone status in postmenopausal American women. Bone. 2007;40(4):1128-1134. doi:10.1016/j. bone.2006.12.001

18. Mazziotti G, Porcelli T, Patelli I, et al. Serum TSH values and risk of vertebral fractures in euthyroid post-menopausal women with low bone mineral density. Bone. 2010;46(3):747-751. doi:10.1016/j. bone.2009.10.031

19. Murphy E, Gluer CC, Reid DM, et al. Thyroid function within the upper normal range is associated with reduced bone mineral density and an increased risk of nonvertebral fractures in healthy euthyroid postmenopausal women. J Clin Endocrinol Metab. 2010;95 (7):3173-3181. doi:10.1210/jc.2009-2630

20. Kim DJ, Khang YH, Koh J-M, et al. Low normal TSH levels are associated with low bone mineral density in healthy postmenopausal women. Clin Endocrinol (Oxf). 2006;64(1):86-90. doi:10.1111/ j.1365-2265.2005.02422.x

21. Noh HM, Park YS, Lee J, et al. A cross-sectional study to examine the correlation between serum TSH levels and the osteoporosis of the lumbar spine in healthy women with normal thyroid function. Osteoporos Int. 2015;26(3):997-1003. doi:10.1007/s00198-0142906-Z

22. Lin JD, Pei D, Hsia T-L, et al. The relationship between thyroid function and bone mineral density in euthyroid healthy subjects in Taiwan. Endocr Res. 2011;36(1):1-8. doi:10.3109/ 07435800.2010 .514877

23. Svare A, Nilsen TIL, Åsvold BO, et al. Does thyroid function influence fracture risk? Prospective data from the HUNT2 study, Norway. Eur J Endocrinol. 2013;169(6):845-852. doi:10.1530/EJE13-0546

24. Grimnes G, Emaus N, Joakimsen RM, et al. The relationship between serum TSH and bone mineral density in men and postmenopausal women: the Tromsø study. Thyroid. 2008;18(11):1147-1155. doi:10.1089/thy.2008.0158

25. Pluijm SM, Visser M, Smit JH, et al. Determinants of bone mineral density in older men and women: body composition as mediator. J Bone Miner Res. 2001;16(11):2142-2151. doi:10.1359/jbmr.2001.16.11.2142

26. Taaffe DR, Cauley JA, Danielson M, et al. Race and sex effects on the association between muscle strength, soft tissue, and bone mineral density in healthy elders: the health, aging, and body composition study. J Bone Miner Res. 2001;16(7):1343-1352. doi:10.1359/jbmr.2001.16.7.1343

27. Siru R, Alfonso H, Chubb SAP, et al. Subclinical thyroid dysfunction and circulating thyroid hormones are not associated with bone turnover markers or incident hip fracture in older men. Clin Endocrinol (Oxf). 2018;89(1):93-99. doi:10.1111/cen.13615

28. Karar T, Alhammad RI, Fattah M, et al. Relation between glycosylated hemoglobin and lipid and thyroid hormone among patients with type 2 diabetes mellitus at King Abdulaziz Medical City, Riyadh. J Nat Sci Biol Med. 2015;6(Suppl 1):S75-9. doi:10.4103/09769668.166091
29. Moura Neto A, Parisi MCR, Alegre SM, et al. Relation of thyroid hormone abnormalities with subclinical inflammatory activity in patients with type 1 and type 2 diabetes mellitus. Endocrine. 2016;51(1):63-71. doi:10.1007/s12020-015-0651-5

30. Inoue M, Tawata M, Yokomori N, et al. Expression of thyrotropin receptor on clonal osteoblast-like rat osteosarcoma cells. Thyroid. 1998;8(11):1059-1064. doi:10.1089/thy.1998.8.1059

31. Abe E, Marians RC, Yu W, et al. TSH is a negative regulator of skeletal remodeling. Cell. 2003;115(2):151-162. doi:10.1016/S00928674(03)00771-2

32. Hase H, Ando T, Eldeiry L, et al. TNFalpha mediates the skeletal effects of thyroid-stimulating hormone. Proc Natl Acad Sci USA. 2006;103(34):12849-12854. doi:10.1073/pnas.0600427103

33. Sun L, Vukicevic S, Baliram R, et al. Intermittent recombinant TSH injections prevent ovariectomy-induced bone loss. Proc Natl Acad Sci U S A. 2008;105(11):4289-4294. doi:10.1073/pnas.0712395105

34. Baliram R, Sun L, Cao J, et al. Hyperthyroid-associated osteoporosis is exacerbated by the loss of TSH signaling. J Clin Invest. 2012;122 (10):3737-3741. doi:10.1172/JCI63948

35. Raisz LG. Pathogenesis of osteoporosis: concepts, conflicts, and prospects. J Clin Invest. 2005;115(12):3318-3325. doi:10.1172/ JCI27071

36. Turner MR, Camacho X, Fischer HD, et al. Levothyroxine dose and risk of fractures in older adults: nested case-control study. BMJ. 2011;342:d2238. doi:10.1136/bmj.d2238

37. Greenspan SL, Greenspan FS. The effect of thyroid hormone on skeletal integrity. Ann Intern Med. 1999;130(9):750-758. doi:10.7326/0003-4819-130-9-199905040-00016

38. Ongphiphadhanakul B, Alex S, Braverman LE, et al. Excessive L-thyroxine therapy decreases femoral bone mineral densities in the male rat: effect of hypogonadism and calcitonin. $J$ Bone Miner Res. 1992;7(10):1227-1231. doi:10.1002/jbmr.5650071015

39. Suwanwalaikorn S, Ongphiphadhanakul B, Braverman LE, et al. Differential responses of femoral and vertebral bones to long-term excessive L-thyroxine administration in adult rats. Eur J Endocrinol. 1996;134(5):655-659. doi:10.1530/eje.0.1340655

40. Suwanwalaikorn S, Van Auken M, Kang MI, et al. Site selectivity of osteoblast gene expression response to thyroid hormone localized by in situ hybridization. Am J Physiol. 1997;272(2 Pt 1):E212-7. doi:10.1152/ajpendo.1997.272.2.E212

41. Ross PD, Wasnich RD, Vogel JM. Detection of prefracture spinal osteoporosis using bone mineral absorptiometry. J Bone Miner Res. 1988;3(1):1-11. doi:10.1002/jbmr.5650030103

42. Orwoll ES, Oviatt SK, Mann T. The impact of osteophytic and vascular calcifications on vertebral mineral density measurements in men. J Clin Endocrinol Metab. 1990;70(4):1202-1207. doi:10.1210/ jcem-70-4-1202

43. Drinka PJ, DeSmet AA, Bauwens SF, et al. The effect of overlying calcification on lumbar bone densitometry. Calcif Tissue Int. 1992;50 (6):507-510. doi:10.1007/BF00582163

44. Resnick D. Degeneration disease of the spine. Diagn Bone Joint Disord. 1981;1374-1380.

Diabetes, Metabolic Syndrome and Obesity: Targets and Therapy

Dovepress

\section{Publish your work in this journal}

Diabetes, Metabolic Syndrome and Obesity: Targets and Therapy is an international, peer-reviewed open-access journal committed to the rapid publication of the latest laboratory and clinical findings in the fields of diabetes, metabolic syndrome and obesity research. Original research, review, case reports, hypothesis formation, expert opinion and commentaries are all considered for publication. The manuscript management system is completely online and includes a very quick and fair peer-review system, which is all easy to use. Visit http://www.dovepress.com/testimonials.php to read real quotes from published authors. 